Boglarka Bansagi, MD

Helen Griffin, PhD

Roger G. Whittaker, MD, $\mathrm{PhD}$

Thalia Antoniadi, PhD

Teresinha Evangelista, MD

James Miller, MD, PhD

Mark Greenslade, PhD

Natalie Forester, PhD

Jennifer Duff, PhD

Anna Bradshaw

Stephanie Kleinle, $\mathrm{PhD}$

Veronika Boczonadi, $\mathrm{PhD}$

Hannah Steele, MD

Venkateswaran Ramesh, MD

Edit Franko, MD, PhD

Angela Pyle, PhD

Hanns Lochmüller, MD,

$\mathrm{PhD}$

Patrick F. Chinnery, MD,

FRCP, FMedSci

Rita Horvath, MD, PhD

Correspondence to

Dr. Horvath:

Rita.Horvath@ncl.ac.uk

\section{Supplemental data} at Neurology.org

\title{
Genetic heterogeneity of motor neuropathies OPEN
}

\section{ABSTRACT}

Objective: To study the prevalence, molecular cause, and clinical presentation of hereditary motor neuropathies in a large cohort of patients from the North of England.

Methods: Detailed neurologic and electrophysiologic assessments and next-generation panel testing or whole exome sequencing were performed in 105 patients with clinical symptoms of distal hereditary motor neuropathy (dHMN, 64 patients), axonal motor neuropathy (motor Charcot-Marie-Tooth disease [CMT2], 16 patients), or complex neurologic disease predominantly affecting the motor nerves (hereditary motor neuropathy plus, 25 patients).

Results: The prevalence of dHMN is 2.14 affected individuals per 100,000 inhabitants (95\% confidence interval 1.62-2.66) in the North of England. Causative mutations were identified in 26 out of 73 index patients (35.6\%). The diagnostic rate in the dHMN subgroup was $32.5 \%$, which is higher than previously reported (20\%). We detected a significant defect of neuromuscular transmission in 7 cases and identified potentially causative mutations in 4 patients with multifocal demyelinating motor neuropathy.

Conclusions: Many of the genes were shared between dHMN and motor CMT2, indicating identical disease mechanisms; therefore, we suggest changing the classification and including $\mathrm{dHMN}$ also as a subcategory of Charcot-Marie-Tooth disease. Abnormal neuromuscular transmission in some genetic forms provides a treatable target to develop therapies. Neurology ${ }^{\circledR}$ 2017;88:1226-1234

\section{GLOSSARY}

$\mathbf{C I}=$ confidence interval; $\mathbf{C M T}=$ Charcot-Marie-Tooth disease; $\mathbf{d H M N}=$ distal hereditary motor neuropathy; $\mathbf{H M N}=$ hereditary motor neuropathy; LED = lower extremity dominance; $\mathbf{M A F}=$ minor allele frequency; $\mathbf{N C S}=$ nerve conduction studies; NGS = next-generation sequencing; NMJ = neuromuscular junction; SMA = spinal muscular atrophy; SMARD1 = spinal muscular atrophy with respiratory distress; WES = whole exome sequencing.

Distal hereditary motor neuropathies (dHMN) are clinically and genetically heterogeneous disorders caused by lower motor neuron dysfunction. ${ }^{1}$ The classic phenotype of $\mathrm{dHMN}$ is a lengthdependent motor weakness and atrophy, initially affecting the intrinsic foot muscles and the peroneal compartment of the leg, frequently leading to foot deformities such as pes cavus, pes planus, and clawing of the toes. ${ }^{2}$ The majority of the cases show a slowly progressive disease course gradually involving proximal leg muscles or affecting intrinsic hand muscles. Variable age at onset, diverse clinical course, and associated neurologic features complicate the phenotype and aid the clinical subclassification. Congenital or infantile-onset forms of weakness and atrophy of the feet and legs with no or very slow disease progression were grouped as spinal muscular atrophy with lower extremity dominance (SMA-LED). Other clinical subgroups of dHMN were classified on the basis of additional features such as diaphragmatic paralysis (dHMN-IV), upper limb predominance (dHMN-V), SMA with respiratory

\footnotetext{
From the MRC Centre for Neuromuscular Diseases and John Walton Muscular Dystrophy Research Centre, Institute of Genetic Medicine (B.B., H.G., T.E., J.D., A.B., V.B., H.S., E.F., A.P., H.L., P.F.C., R.H.), and Institute of Neuroscience (R.G.W., J.M.), Newcastle University, Newcastle upon Tyne; Bristol Genetics Laboratory (T.A., M.G., N.F.), Pathology Sciences, North Bristol NHS Trust, Southmead Hospital; Medical Genetic Center (S.K.), Munich, Germany; Department of Paediatric Neurology (V.R.), Royal Victoria Infirmary, Newcastle upon Tyne Foundation Hospitals NHS Trust; Nuffield Department of Clinical Neurosciences (E.F.), University of Oxford; and Department of Clinical Neurosciences (P.F.C.), Cambridge Biomedical Campus, University of Cambridge, UK.

Go to Neurology.org for full disclosures. Funding information and disclosures deemed relevant by the authors, if any, are provided at the end of the article. The Article Processing Charge was paid by Medical Research Council/Wellcome Trust.

This is an open access article distributed under the terms of the Creative Commons Attribution License 4.0 (CC BY), which permits unrestricted use, distribution, and reproduction in any medium, provided the original work is properly cited.
} 
distress (SMARD1 or dHMN-VI), adult-onset with vocal cord palsy (dHMN-VII), and pyramidal features or X-linked inheritance. ${ }^{3}$

Gene identification in dHMN was previously based on linkage studies in rare extended families. However, recent development of next-generation technology enabled studying isolated patients or small families, and a large number of new disease genes and novel phenotypes have been discovered. ${ }^{4}$ Compared to the 7 genes and 13 chromosomal loci 10 years ago, ${ }^{5,6}$ to date we acknowledge around 30 genes responsible for autosomal dominant, recessive, and X-linked forms of dHMN. To identify the molecular cause of motor neuropathies, we performed detailed clinical investigations and state of the art genetic studies in a large, population-based cohort from the North of England.

METHODS Patients. Between 2010 and 2015, we selected 105 patients out of 461 diagnosed with inherited neuropathies in our genetic neuropathy clinic at Newcastle Hospitals NHS Foundation, which is the catchment area of a total population of 2.99 million. Inclusion of patients was based on the presence of a motor neuropathy/neuronopathy with no or only subclinical sensory changes on electrophysiology. Acquired causes were excluded by detailed laboratory analysis/no response on immunosuppressive therapy. Some affected family members of patients with a confirmed genetic diagnosis were included in this cohort, even if no electrophysiologic data were available.

Standard protocol approvals, registrations, and patient consents. Participants provided written informed consent, approved by local research ethics committees, for all experiments using human participants and for photographs that may be published.

Electrophysiology. We performed electrophysiologic examination in 90 patients according to standard techniques and interpreted by the same expert neurophysiologists. Eight family members did not undergo electrophysiologic studies; 7 patients were tested at different hospitals. Motor and sensory nerve conduction studies (NCS) were performed and qualitative and quantitative analysis of motor unit potentials and spontaneous activity were assessed on EMG. Patient classification into study groups was based on these analyses. Additional assessment of repetitive nerve stimulation and single-fiber EMG were carried out in 27 patients, and the percentage increment or decrement was calculated. EMG was performed using Natus Neurology (Pleasanton, CA) disposable 30-G concentric needles with a bandpass range of $10-10,000 \mathrm{~Hz}$. For single-fiber EMG studies, the low pass filter was increased to $2,000 \mathrm{~Hz}$ and the percentage of fiber pairs showing increased jitter or blocking was calculated.

Molecular genetic analysis. DNA was obtained from peripheral blood. Initially, PMP22 deletion/duplication, MFN2, and GJB1 were excluded in all patients. The multigene panel assay utilizing next-generation sequencing (NGS) was carried out in 46 index patients in the Bristol Genetics Laboratory following the
UK Genetic Testing Network approved criteria. Variant classification was based on Association for Clinical Genetic Science Practice Guidelines (2013). We performed whole exome sequencing (WES) in 40 patients. DNA was fragmented, exomeenriched, and sequenced (Illumina [San Diego, CA] TruSeq $62 \mathrm{Mb}$ and HiSeq 2000, 100 bp paired-end reads). Bioinformatic analysis included duplicate sequence read removal with FastUniq, alignment to UCSC hg19 with BWA $^{8}$ variant detection with FreeBayes, and variant annotation with ANNOVAR. Variants were annotated as exonic/splicing, excluding synonymous variants, with a rare minor allele frequency (MAF $<0.01$ ) in the context of genotype (heterozygous $\mathrm{MAF}<0.001$; homozygous $\mathrm{MAF}<0.01$ ) in several databases downloaded via ANNOVAR (ExAC, NHLBI_ESP6500, cg69) and also in 281 in-house exomes. Protein prediction and evolutionary sequence conservation algorithms downloaded via ANNOVAR were used to analyze the in silico effects following the guidelines of the American College of Medical Genetics and Genomics. " Variants were defined as confirmed pathogenic if they were previously shown to be pathogenic or if they were novel variants in a known neuropathyassociated gene, predicted to be deleterious (affect protein structure or function, highly conserved), and segregated with the disease in at least 1 additional affected family member. ${ }^{10}$ Highly conserved, in silico deleterious rare sequence variants of known or novel genes were determined as possible pathogenic if segregation studies involving at least one additional affected family member could not be carried out. Putative pathogenic variants were confirmed by Sanger sequencing and were tested for segregation.

RESULTS Clinical presentation. We identified 105 patients from 73 families with inherited motor neuropathies. Based on neurologic and electrophysiologic findings, all patients were classified into 1 of 3 subgroups: dHMN, motor predominant Charcot-MarieTooth disease (CMT2) (motor CMT2), and motor neuropathy with additional neurologic symptoms (hereditary motor neuropathy [HMN] plus). Diagnosis of dHMN was based on preserved sensory nerve studies with normal or reduced compound motor unit action potentials or neurogenic changes on EMG examination. ${ }^{2}$ Patients with dHMN but with decreased sensory nerve action potentials, indicative of an accompanying sensory axonopathy, were grouped as motor CMT2. We considered HMN plus when motor neuropathy was the leading feature, but was accompanied by other neurologic symptoms. NCS data of all patients are available on request.

All patients seen in our center were from our catchment area (2.99 million people in 2011 UK census), leading to a minimum prevalence of $\mathrm{dHMN}$ as 2.14 affected individuals per 100,000 inhabitants (95\% confidence interval [CI] 1.62-2.66).

Sixty-four out of 105 patients (60.9\%) had dHMN. Sixteen patients had motor CMT2 (15.2\%) and 25 HMN plus (23.8\%) (figures 1-3). There was male predominance in all phenotypic groups. Symptoms started at a younger age in $\mathrm{dHMN}$ (mean 16 years) and HMN plus (mean 17.6 years) compared to motor CMT2 (mean 23.8 years). The main inheritance pattern was autosomal dominant in CMT2 (7/10 families [70\%]) 

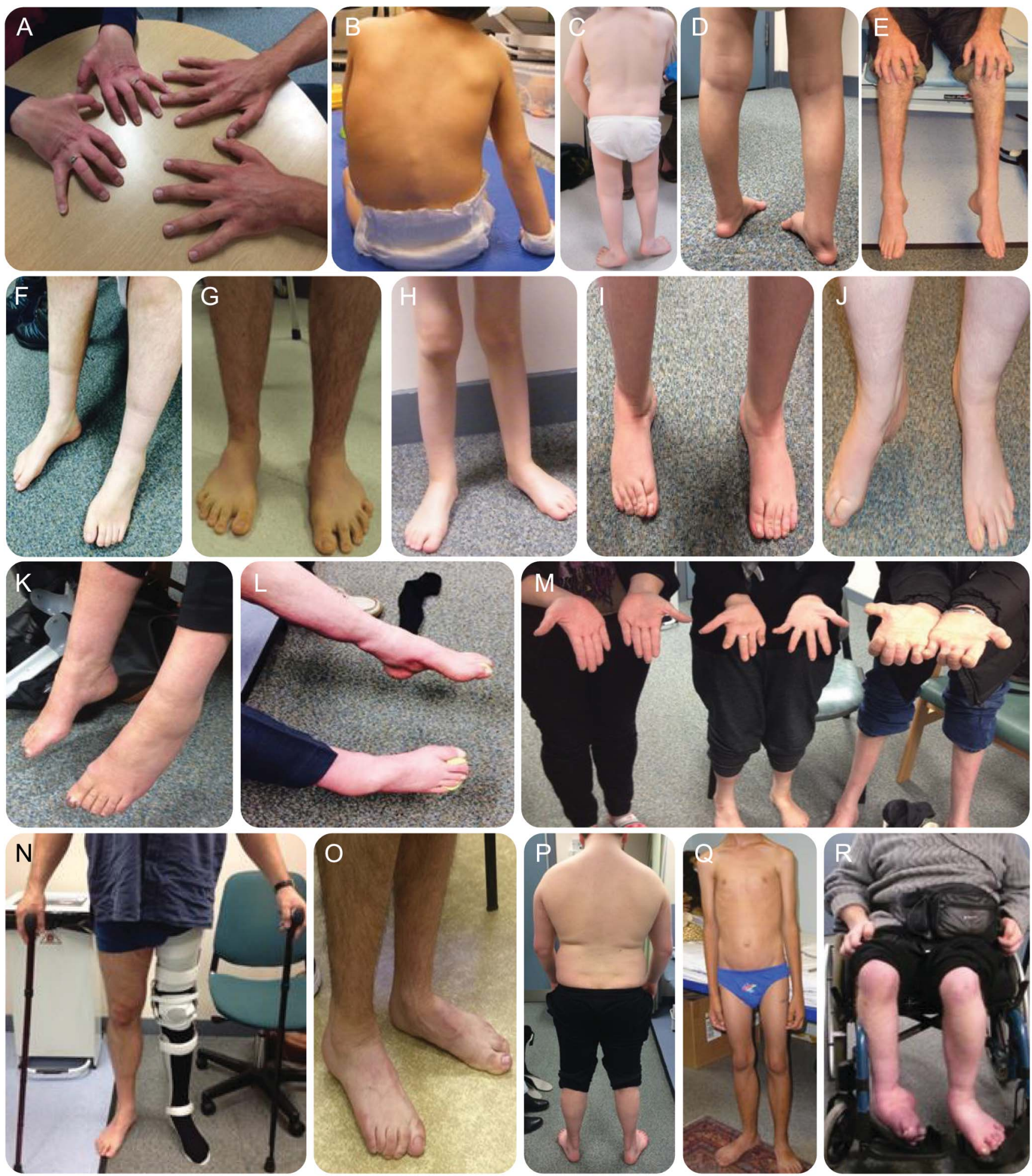

Distal hereditary motor neuropathy (dHMN) (top 2 rows), motor Charcot-Marie-Tooth disease 2 (CMT2) (third row), and HMN plus (bottom row): (A) patients 2 and 3: GARS; (B) patient 19: IGHMBP2; (C) patient 23: TRPV4; (D) patient 32: IGHMBP2; (E) not yet diagnosed dHMN; (F) patient 18: DYNC1H1; (G) patient 10: SYT2; (H) patient 16: BICD2; (I, J) not yet diagnosed spinal muscular atrophy lower extremity dominance; (K) patient 42: AARS; (L) patient 39: AARS; (M) family 22: DNM2; (N) patient 51: FUS; (O) patient 53: ATP7A; (P) patient 57: TBX5; (Q) patient 58: STAT5B; (R) not yet diagnosed HMN plus.

while isolated cases were more frequent in HMN plus. The dHMN group consisted of an almost equal number of dominant families $(\mathrm{n}=16)$ and isolated patients with negative or unavailable family history $(\mathrm{n}=20)$.
We identified causative mutations in 26 out of 73 families, providing a $35.6 \%$ mutation detection rate (figure 2). Candidate gene sequencing based on clinical presentation led to the molecular diagnosis in 
A
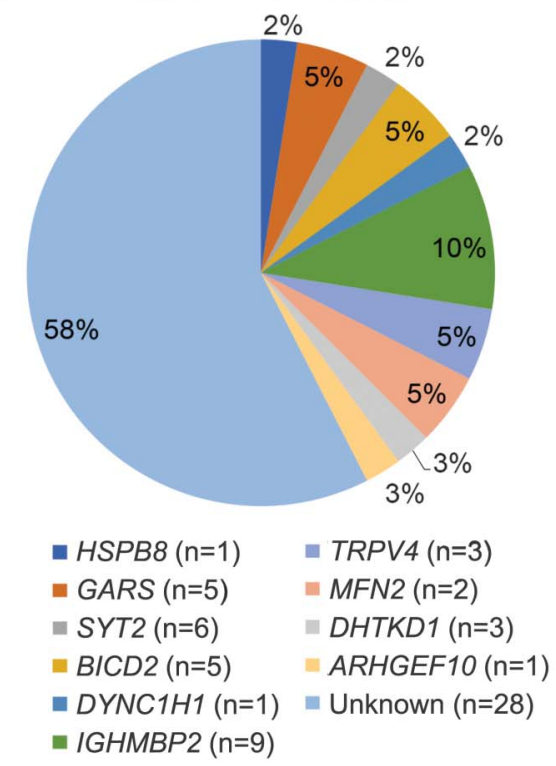

\section{Motor CMT2 7/10 families}

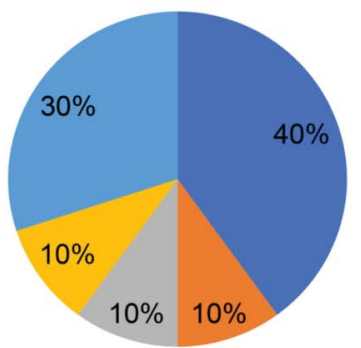

- $A A R S(\mathrm{n}=6)$

- DNM2 $(\mathrm{n}=3)$

$=\operatorname{MFN2}(\mathrm{n}=1)$

MORC2 $(n=2)$

- Unknown $(\mathrm{n}=4)$

\section{HMN plus 11/23 families}

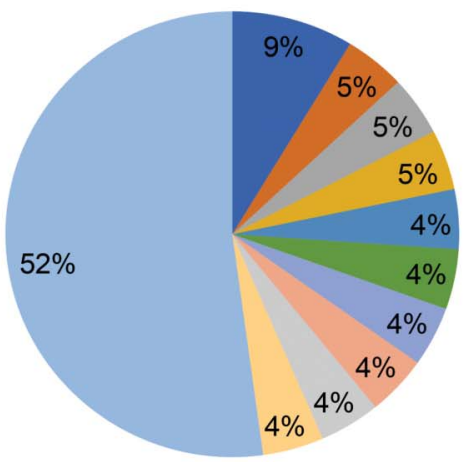

$$
\begin{aligned}
& \text { - SLC52A2/A3 }(n=2) \quad \text { FIG4 }(n=1) \\
& \text { - c12orf65 }(\mathrm{n}=1) \quad \operatorname{TBX5}(\mathrm{n}=1) \\
& \text { - FUS }(n=1) \quad \operatorname{STAT5B}(n=2) \\
& \square \operatorname{DCTN1}(\mathrm{n}=1) \quad \square \operatorname{PTEN}(\mathrm{n}=1) \\
& \text { - } \operatorname{ATP7A}(\mathrm{n}=1) \quad \text { Unknown }(\mathrm{n}=13) \\
& \text { - SACS }(\mathrm{n}=1)
\end{aligned}
$$

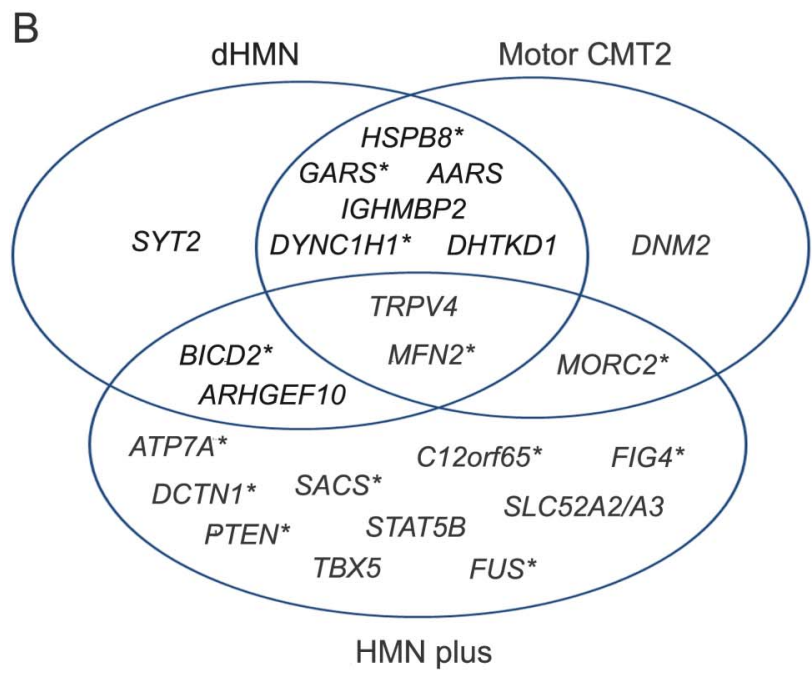

\begin{tabular}{|l|l|}
\hline Genes & Differential diagnostic clues \\
\hline ATP7A & Spastic tetraparesis, ataxia, dystonia, basal ganglia changes \\
\hline DCTN1 & Ataxia, extrapyramidal syndrome of tremor and focal dystonia \\
\hline SACS & Spastic ataxia, Charlevoix-Saguenay type (ARSACS) \\
\hline c120rf65 & Behr syndrome \\
\hline SLC52A2/A3 & Brown-Vialetto-Van Laere syndrome (BVVL) \\
\hline FIG4 & Bilateral optic atrophy, CMT6 \\
\hline FUS & Early-onset ALS with frontotemporal dementia \\
\hline PTEN & Macrocephaly, segmental overgrowth, skin hamartoma, autism \\
\hline STAT5B & Growth retardation (GH-insensitive), craniofacial dysmorphia \\
\hline TBX5 & Holt-Oram syndrome \\
\hline
\end{tabular}

(A) Spectrum and distribution of mutated genes detected in our cohort within the 3 phenotypic groups. (B) Overlapping clinical phenotypes related to the identified genes and key additional clinical features associated. *Upper motor neuron involvement. ALS = amyotrophic lateral sclerosis.

5 out of 105 patients only (4.7\%), while 12 index patients were diagnosed by NGS panel from 46 performed tests $(26 \%)$ and a further 18 index patients by WES (total 40 analysis) (45\%). There were no novel shared genes/mutations in the exome negative cases.

Mutation spectrum in dHMN. We achieved the possible genetic diagnosis in 17/40 families, which resulted in $42.5 \%$ detection rate (figure 2). Variants were considered confirmed pathogenic in 13 index cases $(32.5 \%)$; 7 of them carried known pathogenic dHMN mutations while in 6 families novel deleterious variants were detected in known genes and segregated with the phenotype (table e-1A at Neurology.org).
A previously reported heterozygous c. $421 \mathrm{~A}>\mathrm{G}$, p.(Lys141Glu) mutation in HSPB8 presented with a progressive lower limb predominant phenotype (family 1). We found 2 novel GARS mutations in 2 independent families (families 2-3). The heterozygous c.647A $>\mathrm{G}$, p.(His216Arg) was detected in a mother and her son with predominant upper extremity involvement (dHMN-V) (figure 1A). The c. $1528 \mathrm{~A}>\mathrm{C}$, p.(Lys510Gln) mutation cosegregated in 3 generations with dominant distal motor neuropathy affecting both upper and lower extremities. Electrophysiologic examination revealed mildly increased jitter in one patient consistent with a motor neuropathy and significantly increased jitter with blocking in another patient. One patient with dHMN involving 
Figure 3 Diagnostic flow chart and mutation detection rates in our hereditary motor neuropathy (HMN) cohort

\begin{tabular}{|c|c|c|c|c|c|c|c|c|c|c|c|c|c|c|}
\hline & \multirow{2}{*}{$\begin{array}{l}\text { Patients } \\
\text { Number }\end{array}$} & \multirow{2}{*}{$\begin{array}{l}\text { Family } \\
\text { Number }\end{array}$} & \multicolumn{3}{|c|}{ Patient distribution } & \multicolumn{3}{|c|}{ Positive diagnostic genetic test } & \multicolumn{3}{|c|}{ Genetic diagnosis in families } & \multicolumn{2}{|c|}{$\begin{array}{c}\text { Mutation } \\
\text { detection rate }\end{array}$} & \multirow{2}{*}{\begin{tabular}{|c|}
$\begin{array}{c}\text { Summary } \\
\text { detection } \\
\text { rate }\end{array}$ \\
$\begin{array}{c}\text { Confirmed } \\
\text { + Possible }\end{array}$ \\
\end{tabular}} \\
\hline & & & Phenotype & $\mathrm{M} / \mathrm{F}$ & $\begin{array}{c}\text { Age } \\
\text { onset } \\
\text { (Years) }\end{array}$ & $\begin{array}{l}\text { Target test } \\
\text { (Total 296) }\end{array}$ & $\begin{array}{l}\text { Panel test } \\
\text { (Total 46) }\end{array}$ & $\begin{array}{c}\text { WES } \\
\text { (Total 40) }\end{array}$ & $\begin{array}{l}\text { Confirmed } \\
\text { genes }\end{array}$ & $\begin{array}{c}\text { Possible } \\
\text { genes }\end{array}$ & Unknown & Confirmed & Possible & \\
\hline dHMN & 64 & 40 & $60.9 \%$ & $\begin{array}{l}39 / \\
25\end{array}$ & 16 & $3 / 169$ & $5 / 25$ & $9 / 22$ & 13 & 4 & 23 & $32.5 \%$ & $10 \%$ & $42.5 \%$ \\
\hline $\begin{array}{l}\text { Motor } \\
\text { CMT2 }\end{array}$ & 16 & 10 & $15.2 \%$ & $11 / 5$ & 23.8 & $0 / 40$ & $6 / 10$ & $1 / 3$ & 7 & - & 3 & $70 \%$ & - & $70 \%$ \\
\hline $\begin{array}{l}\text { dHMN } \\
\text { plus }\end{array}$ & 25 & 23 & $23.8 \%$ & $20 / 5$ & 17.6 & $2 / 87$ & $1 / 11$ & $8 / 15$ & 6 & 5 & 12 & $26 \%$ & $21.7 \%$ & $47.7 \%$ \\
\hline Summary & 105 & 73 & $100 \%$ & $\begin{array}{l}70 / \\
35\end{array}$ & 17.6 & $5 / 296$ & $12 / 46$ & $18 / 40$ & 26 & 9 & 38 & $35.6 \%$ & $12.3 \%$ & $47.9 \%$ \\
\hline
\end{tabular}

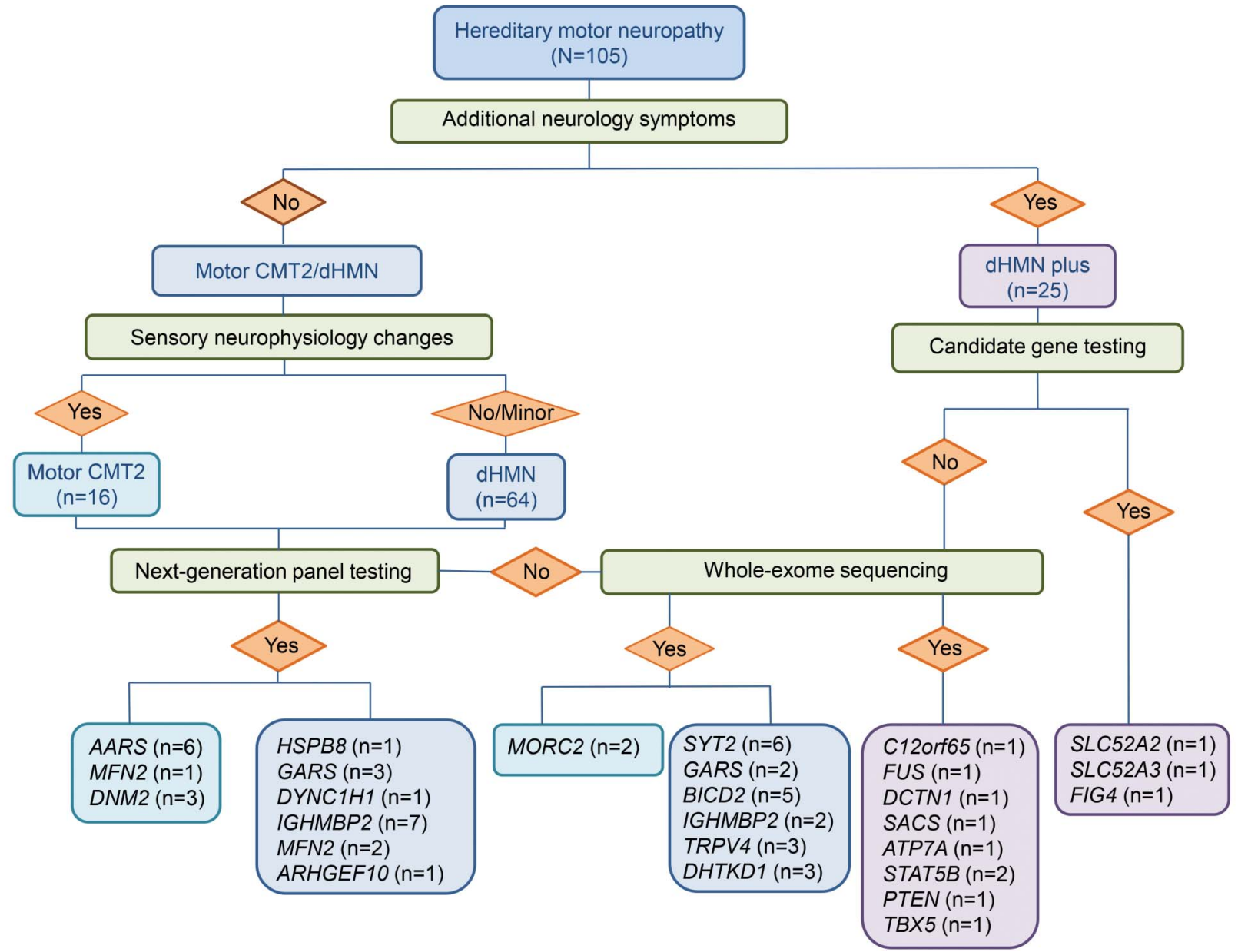

$\mathrm{CMT}=$ Charcot-Marie-Tooth disease $; \mathrm{dHMN}=$ distal hereditary motor neuropathy WES $=$ whole exome sequencing.

both upper and lower limbs carried the previously reported c. $1834 \mathrm{G}>\mathrm{A}$, p.(Val612Met) mutation in DYNC1H1 (family 7) (figure $1 \mathrm{~F})$. A rapidly progressive $\mathrm{dHMN}$ in a 15 -year-old boy was due to the de novo previously reported c.1126A $>$ G, p. (Met376Val) mutation in MFN2 (family 12). ${ }^{11}$ The heterozygous c.2119C $>\mathrm{T}$ p.(Arg707Trp) MFN2 mutation was found in a 70- year-old man with late-onset dHMN (family 13). ${ }^{12}$

The homozygous frameshift c.292_303delinsATGCT p.(Gly98fs) mutation in IGHMBP2 led to SMARD1 in 2 siblings of consanguineous Pakistani origin (family 8) (figure 1B). A brother and sister from another family with childhood-onset distal SMA and lack of respiratory involvement carried a heterozygous c. $1813 \mathrm{C}>\mathrm{T}$ p. $\left(\operatorname{Arg} 605^{*}\right)$ nonsense IGHMBP2 mutation, which was hemizygous in the cDNA (family 9). ${ }^{13}$

We have previously reported 6 patients with nonprogressive neuropathy and fatigable weakness carrying c.923C > T; p.(Pro308Leu) in SYT2 (family 4) (figure $1 \mathrm{G}),{ }^{14} 5$ patients with distal congenital nonprogessive 
SMA carrying c.320C $>\mathrm{T}$, p.(Ser107Leu) in BICD2 (families 5-6) (figure $1 \mathrm{H}),{ }^{15}$ and 2 patients with TRPV4 mutations associated with childhood-onset scapuloperoneal SMA and metatropic dysplasia (family 10) (figure 1C) or adult-onset dHMN (family 11). ${ }^{16}$

Possibly causative mutations were detected in 4 families (table e-1B). The heterozygous novel c.2752C $>$ T, p.(Arg918Cys) IGHMBP2 variant was detected in 3 siblings with motor neuropathy, without respiratory dysfunction (family 14). All prediction tools predicted this change pathogenic, and it was absent in the ExAC database, although we could not identify a second mutation in this family. The single heterozygous c.767C $>$ G, p.(Ala256Gly) $I G H M B P 2$ variant was detected in a 3.5-year-old boy with compatible phenotype (family 15) (figure 1D). In 3 members of a dominant $\mathrm{dHMN}$ pedigree (family 16), we found a novel heterozygous DHTKD1 variant c.628G $>$ T, p.(Ala210Ser). In a young female patient (family 17) we identified a heterozygous novel c.1949G $>$ A, p.(Tyr650Cys) sequence change in ARHGEF10.

Mutation spectrum in motor CMT2. Motor CMT2 was considered in 16 patients from 10 families. We achieved $70 \%$ mutation detection rate in this group by concluding molecular diagnosis in 7 CMT2 families (figure 2) (table e-2). We identified the recurrent c.986G $>$ A, p.(Arg329His) AARS mutation in 6 patients from 4 families (families 18-21) (figure 1, K and L). ${ }^{17}$ In 3 members of a dominant family with early-onset intermediate motor neuropathy, split hand deformity, and hearing loss, we detected the previously described c.1739T $>$ C, p.(Met580Thr) DNM2 mutation (family 22) (figure $1 \mathrm{M}){ }^{18} \mathrm{~A}$ female patient with upper limb weakness carried the pathogenic c.1403G $>$ A, p.(Arg468His) MFN2 mutation (family 23). ${ }^{12}$ Exome sequencing of male monozygotic twins with early-onset severe motor predominant neuropathy revealed the recently reported heterozygous c.754C $>\mathrm{T}$, p.(Arg252Trp) mutation in the MORC2 gene (family 24). ${ }^{19}$

Mutation spectrum in HMN plus families. Twenty-five patients from 23 families with predominant motor neuropathy had additional neurologic features. Confirmed pathogenic mutations were detected in 6 patients $(26 \%)$ and a probable disease cause was identified in a further 5 index patients $(21.7 \%$ ) (figure 2, table e-3A). The heterozygous c.1529A $>\mathrm{G}$ p.(Lys510Arg) FUS mutation was detected in a 52-year-old man with asymmetric lower limb motor neuropathy. The progression was rapid with evolving motor neuron disease, frontal dementia, and loss of ambulation within half a year (family 27) (figure $1 \mathrm{~N})$. WES identified a hemizygous c.2279A $>\mathrm{G}$, p.(Tyr760Cys) novel ATP7A variant with upper and lower motor neuron symptoms (family 29) (figure 1O). ${ }^{20}$ We detected compound heterozygous c.916G $>$ A, p.(Gly306Arg) and c.1016T $>$ C, p. (Leu339Pro) mutations in SLC52A2 (family 25) 21 and a homozygous c.96_99dupATCC, p.(Pro34llefs*25) mutation in the c12orf65 gene (family 26). ${ }^{22}$ Distal motor neuropathy with ataxia and dystonia was associated with c.3823C $>\mathrm{T}$ p.(Arg1275Cys) in DCTN1 (family 28). ${ }^{23}$ Compound heterozygous c. $1580 \mathrm{C}>\mathrm{G}, \quad$ p. $($ Ser527*) and c.6781C $>$ A, p.(Leu2261Ile) mutations in SACS caused juvenileonset motor neuropathy, ataxia, and spasticity in a 71year-old man (family 30). ${ }^{24}$ Possibly causative mutations were detected in 5 families (table e-3B). A 17-year-old man with distal motor neuropathy and optic atrophy (CMT type 6) carried a single previously reported heterozygous c.2386C $>\mathrm{T}$, p. $\left(\mathrm{Gln} 796^{*}\right)$ mutation in FIG4. ${ }^{25}$ Heterozygous FIG4 mutations have been associated with adult-onset amyotrophic lateral sclerosis but without optic atrophy. ${ }^{26} \mathrm{We}$ found the heterozygous c.1371C $>$ G, p.(Phe457Leu) mutation in SLC52A3 in a 19-year-old man with Brown-Vialetto-Van-Laere syndrome, who responded well to riboflavin therapy. However, we could not identify a second mutation, even by analyzing WES for copy number variations within this gene (family 32). A 19-year-old man with shoulder girdle weakness commonly seen in HoltOram syndrome carried the previously reported c.331G $>$ T, p.(Asp111Tyr) TBX5 mutation (family 33, figure $1 \mathrm{P}) .{ }^{27} \mathrm{We}$ identified the novel homozygous c. $944 \mathrm{~T}>\mathrm{G}$, p.(Glu315Ala) mutation in the transcriptional factor $S T A T 5 B$ in a sibling pair from a consanguineous family with growth retardation, dysmorphic face, and motor neuropathy (family 34) (figure 1Q). Asymmetric motor neuron weakness, cranial nerve involvement, pyramidal signs, and multifocal motor neuropathy with conduction blocks were observed in a man who carried a novel de novo c.269T $>$ C, p.(Phe90Ser) mutation in PTEN (family 35).

DISCUSSION Although HMNs are suggested to be rare, we identified 105 patients in the North of England, with a population of 2.99 million. We previously determined that the minimum prevalence of CMT in the North of England is 11.8 per 100,000 individuals. ${ }^{28,29}$ Here we report that the minimum prevalence of $\mathrm{dHMN}$ in the same population is 2.14 affected individuals per 100,000 inhabitants (95\% CI 1.62-2.66), which is higher than suggested earlier. $^{29,30}$

Previous studies indicated that the molecular cause can be identified in the vast majority of patients with demyelinating CMT; however, the detection rate has been much lower in dHMN and motor CMT2 $(\sim 20) .{ }^{3}$ We identified potentially pathogenic mutations in $47.9 \%$ (35/73 families), which consisted of 
confirmed mutations in $35.6 \%$ and possibly causative variants in an additional $12.3 \%$. Previously in dHMN, the detection rate was $15 \%-20 \%$. $^{3,5,6,31}$ We confirmed genetic diagnosis in $32.5 \%$ (13/40 families) of $\mathrm{dHMN}$, and a likely causative mutation was identified in an additional 10\% (figure 2), which is higher than in previous studies (tables e-4-e-6).

$\mathrm{dHMN}$ is strictly considered as the pure motor end of CMT, many patients show minor sensory abnormalities, ${ }^{1,6}$ and mutations in the same gene can cause both dHMN and CMT2., ${ }^{2,31}$ HMN may be complicated by SMA, spastic paraplegia, or other neurologic abnormalities. ${ }^{1,6,32}$ Affected pathways linked to dHMN include DNA/RNA metabolism, protein translation and synthesis, stress response, apoptosis, axonal guidance, intracellular trafficking, and synaptic activity (figure 4). Mitochondrial abnormalities are common in our cohort in all forms of motor neuropathies and contribute to the symptoms by altering mitochondrial fusion/fission (MFN2, DNM2, SLC25A46), axonal transport (HSPB1, HSPB8), protein synthesis (C12orf65, $S A C S$ ), or cofactors (SLC52A2/3).

SMA-LED has been introduced to characterize the congenital or early childhood-onset nonprogressive atrophy and weakness of the legs affecting both distal and proximal muscles, caused by altered motor neuron development or function. ${ }^{3}$ The clinical presentation may overlap between spinal and distal motor neuron dysfunction. Correction of deformities is important, since these patients do not deteriorate in the later disease course. We identified 17 patients with clinical symptoms resembling SMA-LED, carrying mutations in SYT2, BICD2, and DYNC1H1, and no causative mutation was identified in 4 patients (figure 1, I-J). No major common pathway can be highlighted by the pathomechanism of these genes, while different mutations in the same gene (such as DYNC1H1) may also cause different clinical presentations.

We reported that mutations in synaptic proteins can cause nonprogressive motor neuropathy and fatigable weakness with presynaptic neuromuscular junction (NMJ) defect (SYT2), ${ }^{15}$ which can benefit from 3,4 diaminopyridine treatment. ${ }^{33}$ Abnormal neuromuscular transmission has been shown in Drosophila and mouse models of GARS mutations. ${ }^{34,35}$ Furthermore, a genetic defect of the presynaptic choline transport leads to HMN due to SLC5A7 mutations. ${ }^{36}$ Based on these findings, we studied neuromuscular transmission in 27 patients and substantial abnormalities (over and above that expected in the context of immature NMJs formed during denervation and reinnervation) were detected in 7 cases harboring different gene mutations. Further detailed studies of the NMJ are warranted, including genetically characterized patients. Neuromuscular transmission can be

Figure 4 Pathomechanisms of genes reported in hereditary motor neuropathy (HMN)

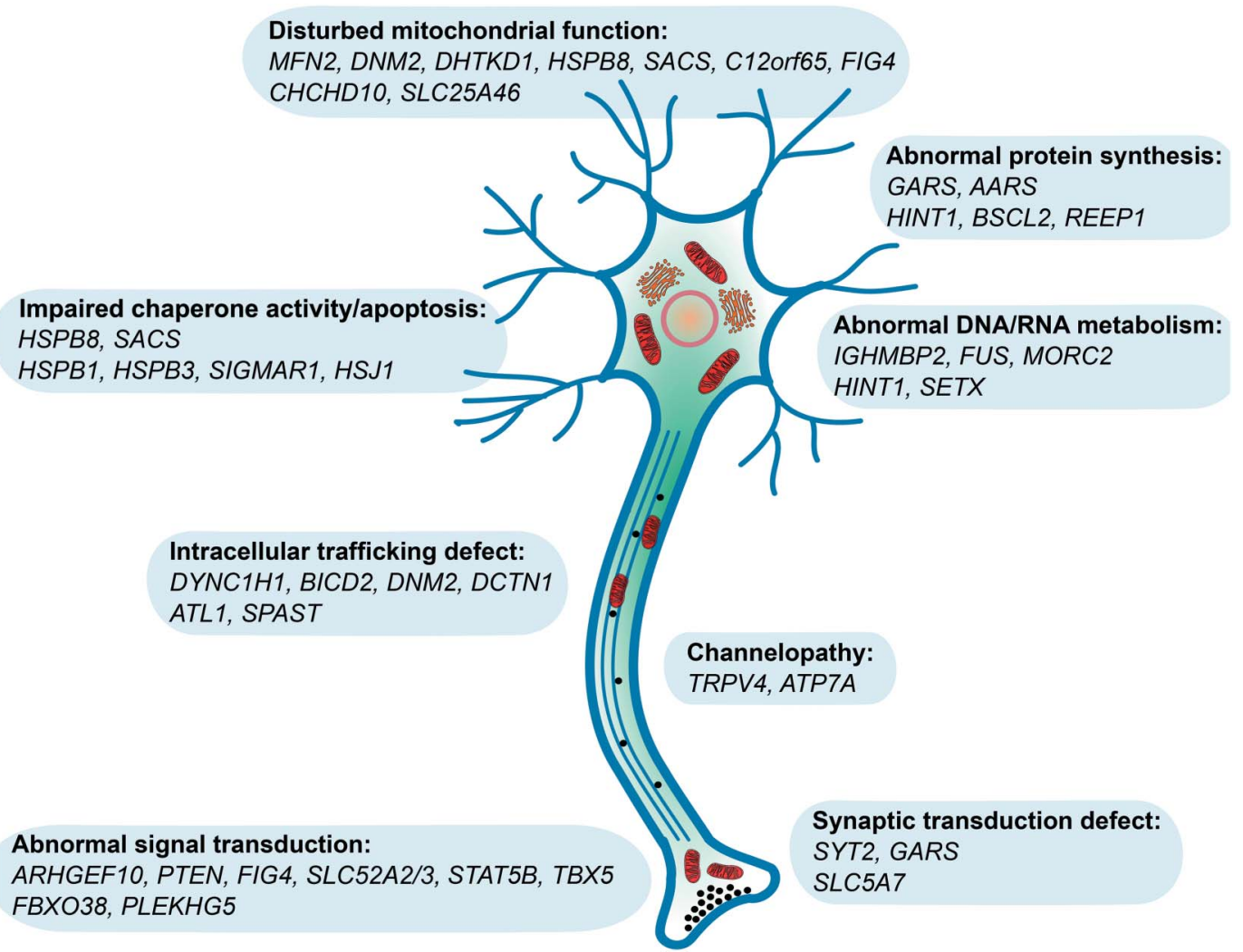


modified by several, already available compounds, which have been broadly used in congenital myasthenic syndromes, but not in hereditary neuropathies. We suggest performing repetitive stimulation and single fiber EMG as part of routine electrophysiologic studies in patients with HMN in order to uncover potentially treatable transmission defects.

We identified a subgroup of patients with inherited motor neuropathy, resembling multifocal demyelinating motor neuropathy or nodo-paranodopathy. Talipes and pure motor nerve involvement were caused by a novel mutation in ARHGEF10. Slow nerve conduction velocities have been implicated in ARHGEF10 mutations and a 10-bp deletion in Leonberger dogs led to pelvic muscle weakness, stepping gait, and recurrent laryngeal nerve palsy. ${ }^{37}$

A previously reported pathogenic mutation in TBX5 was detected in a patient with demyelinating multifocal motor neuropathy. TBX5 participates in transcriptional regulatory cascades and its pathogenic mutations, located within the DNA binding T-box domain, manifest in a rare condition called HoltOram syndrome with deformity of upper limbs, carpal tunnel syndrome, and cardiac anomalies. ${ }^{27} \mathrm{We}$ suggest that TBX5 may cause demyelinating neuropathy affecting predominantly the motor nerves. No cardiac symptoms were detected in our patient. We detected a novel possibly causative $S T A T 5 B$ mutation in a sibling pair with motor neuropathy, ptosis, short stature, and dysmorphic facial features. Homozygous mutations in STAT5B, a signal transducer and activator of transcription, have been reported in only a handful of patients worldwide, all manifesting with postnatal growth retardation and occasional immunologic alterations. ${ }^{38}$ Impaired $S T A T 5 B$ signaling may lead to aberrant peripheral myelination through cyclin D1 overexpression and may have an effect on neuronal growth and differentiation. ${ }^{39}$ Finally, we detected a possibly causative de novo PTEN mutation in a patient with patchy motor neuropathy, focal demyelination, hamartomalike skin lesions, and autism spectrum disorder. PTEN, a lipid phosphatase, inhibits phosphoinositide 3kinase, which is also impaired in several forms of CMT (FIG4, FGD4, MTMR2, MTMR13/SBF2). It has been implicated in peripheral neural plasticity, axonal outgrowth, and hypermyelination. Experimental PTEN suppression in mice resulted in progressive peripheral neuropathy with tomacula formation and myelin outfoldings. ${ }^{40}$

The identification of pathogenic mutations in the same genes in $\mathrm{dHMN}$ and motor CMT indicate that dHMN should not be classified as a different disease group. The detection of mutations in rare disease genes, not implicated in neuropathy to date, suggest that the neuropathy can be part of a more complex genetic disease and key clinical signs are important to recognize these diseases. These overlapping phenotypes highlight basic biological pathways in peripheral nerves that may be targeted to develop therapies for patients with inherited motor neuropathies.

\section{AUTHOR CONTRIBUTIONS}

Boglarka Bansagi: drafting the manuscript, study concept and design, acquisition, analysis and interpretation of data. Helen Griffin: analysis and interpretation of data. Roger Whittaker: analysis and interpretation of data. Thalia Antoniadi: analysis and interpretation of data. Teresinha Evangelista: analysis and interpretation of data. James Miller: analysis and interpretation of data. Mark Greenslade: analysis and interpretation of data. Natalie Forester: analysis and interpretation of data. Jennifer Duff: analysis and interpretation of data. Anna Bradshaw: analysis and interpretation of data. Stephanie Kleinle: analysis and interpretation of data. Veronika Boczonadi: analysis and interpretation of data. Hannah Steele: analysis and interpretation of data. Venkatateswaran Ramesh: analysis and interpretation of data. Edit Franko: analysis and interpretation of data. Angela Pyle: analysis and interpretation of data. Hanns Lochmüller: analysis and interpretation of data, critical correction of the manuscript. Patrick F. Chinnery: analysis and interpretation of data, critical correction of the manuscript. Rita Horvath: study funding, drafting/revision of the manuscript, study concept and design, acquisition, analysis and interpretation of data.

\section{ACKNOWLEDGMENT}

The authors thank the members of the clinical team at the John Walton Muscular Dystrophy Research Centre (Newcastle), who may have seen some of the patients included in this cohort; the Northern Genetic Service and the UKGTN for providing diagnostic testing for some patients in this collective; and the Medical Research Council (MRC) Centre for Neuromuscular Diseases Biobank Newcastle and EuroBioBank for supporting this project.

\section{STUDY FUNDING}

RH is a Wellcome Trust Investigator (109915/Z/15/Z), who receives support from the Medical Research Council (UK) (MR/N025431/1), the European Research Council (309548), the Wellcome Trust Pathfinder Scheme (201064/Z/16/Z), and the Newton Fund (UK/Turkey, MR/N027302/1). B.B. is a Medical Research Council (MRC)-funded Clinical Research Fellow and receives support from the MRC Centre for Neuromuscular Diseases. H.L. receives funding from the European Union Seventh Framework Programme (FP7/2007-2013) under grant agreement no. 305444 (RD-Connect) and 305121 (Neuromics). P.F.C. is a Wellcome Trust Senior Fellow in Clinical Science (101876/Z/13/Z) and a UK NIHR Senior Investigator, who receives support from the MRC Mitochondrial Biology Unit (MC_UP_1501/2), the Wellcome Trust Centre for Mitochondrial Research (096919Z/11/Z), the MRC (UK) Centre for Translational Muscle Disease (G0601943), EU FP7 TIRCON, and the NIH Research (NIHR) Biomedical Research Centre based at Cambridge University Hospitals NHS Foundation Trust and the University of Cambridge. The views expressed are those of the authors and not necessarily those of the NHS, the NIHR, or the Department of Health.

\section{DISCLOSURE}

The authors report no disclosures relevant to the manuscript. Go to Neurology.org for full disclosures.

Received September 5, 2016. Accepted in final form January 6, 2017.

\section{REFERENCES}

1. Rossor AM, Kalmar B, Greensmith L, Reilly MM. The distal hereditary motor neuropathies. J Neurol Neurosurg Psychiatry 2012;83:6-14.

2. De Jonghe P, Timmerman V, Van Broeckhoven C, et al. 2nd workshop of the European CMT consortium: 53rd ENMC international workshop on classification and diagnostic guidelines for Charcot-Marie-Tooth type 2 (CMT2HMSN II) and distal hereditary motor neuropathy (distal 
HMN-spinal CMT), 26-28 September 1997, Naarden, the Netherlands. Neuromuscul Disord 1998;8:426-431.

3. Rossor AM, Evans MR, Reilly MM. A practical approach to the genetic neuropathies. Pract Neurol 2015;15:187-198.

4. Timmerman V, Strickland AV, Züchner S. Genetics of Charcot-Marie-Tooth (CMT) disease within the frame of the human genome project success. Genes2014;5:13-32.

5. Irobi J, De Jonghe P, Timmerman V. Molecular genetics of distal hereditary motor neuropathies. Hum Mol Gen 2004;13:195-202.

6. Irobi J, Dierick I, Jordanova A, et al. Unraveling the genetics of distal hereditary motor neuronopathies. Neuromolecul Med 2006;8:131-146.

7. Xu H, Luo X, Qian J, et al. FastUniq: a fast de novo duplicates removal tool for paired short reads. PLoS One 2012;7:e52249.

8. Li H, Durbin R. Fast and accurate short read alignment with Burrows-Wheeler transform. Bioinformatics 2009; 25:1754-1760.

9. Rehm HL, Bale SJ, Bayrak-Toydemir P, et al; Working Group of the American College of Medical Genetics and Genomics Laboratory Quality Assurance Committee. ACMG clinical laboratory standards for next-generation sequencing. Genet Med 2013;15:733-747.

10. Pyle A, Smertenko T, Bargiela D, et al. Exome sequencing in undiagnosed inherited and sporadic ataxias. Brain 2015; 138:276-283.

11. Casasnovas C, Banchs I, Cassereau J, et al. Phenotypic spectrum of MFN2 mutations in the Spanish population. J Med Genet 2010;47:249-256.

12. Nightingale H, Pfeffer G, Horvath R. Chronic and slowly progressive weakness of the legs and hands. BMJ 2014; 348:g459.

13. Cottenie E, Kochanski A, Jordanova A, et al. Truncating and missense mutations in IGHMBP2 cause CharcotMarie Tooth disease type 2. Am J Hum Genet 2014;95: 590-601.

14. Herrmann DN, Horvath R, Sowden JE, et al. Synaptotagmin 2 mutations cause an autosomal-dominant form of Lambert-Eaton myasthenic syndrome and nonprogressive motor neuropathy. Am J Hum Genet 2014;95:332-339.

15. Bansagi B, Griffin H, Ramesh V, et al. The p.Ser107Leu in BICD2 is a mutation "hot spot" causing distal spinal muscular atrophy. Brain 2015;138:e391.

16. Evangelista T, Bansagi B, Pyle A, et al. Phenotypic variability of TRPV4-related neuropathies. Neuromuscul Disord 2015;25:516-521.

17. Bansagi B, Antoniadi T, Burton-Jones S, et al. Genotype/phenotype correlations in AARS-related neuropathy in a cohort of patients from the United Kingdom and Ireland. J Neurol 2015;262:1899-1908.

18. Haberlova J, Mazanec R, Ridzon P, et al. Phenotypic variability in a large Czech family with a dynamin 2-associated Charcot-Marie-Tooth neuropathy. J Neurogenet 2011;25:182-188.

19. Albulym OM, Kennerson ML, Harms MB, et al. MORC2 mutations cause axonal Charcot-Marie-Tooth disease with pyramidal signs. Ann Neurol 2016;79:419-427.

20. Bansagi B, Lewis-Smith DJ, Pal E, et al. Phenotypic convergence of Menkes and Wilson's disease. Neurol Genet 2016;2:e119.

21. Foley AR, Menezes MP, Pandraud A, et al. Treatable childhood neuronopathy caused by mutations in riboflavin transporter RFVT2. Brain 2014;137:44-56.
22. Pyle A, Ramesh V, Bartsakoulia M, et al. Behr's syndrome is typically associated with disturbed mitochondrial translation and mutations in the C12orf65 gene. J Neuromuscul Dis 2014;1:55-63.

23. Daud D, Griffin H, Douroudis K, et al. Whole exome sequencing and the clinician: we need clinical skills and functional validation in variant filtering. J Neurol 2015; 262:1673-1677.

24. Yu-Wai-Man P, Pyle A, Griffin H, et al. Abnormal retinal thickening is a common feature among patients with ARSACS-related phenotypes. Br J Ophthalmol 2014;98: 711-713.

25. DiVincenzo C, Elzinga CD, Medeiros AC, et al. The allelic spectrum of Charcot-Marie-Tooth disease in over 17,000 individuals with neuropathy. Mol Genet Genomic Med 2014;2:522-529.

26. Chow CY, Landers JE, Bergren SK, et al. Deleterious variants of FIG4, a phosphoinositide phosphatase, in patients with ALS. Am J Hum Genet 2009;84:85-88.

27. Heinritz W, Shou L, Moschik A, Froster UG. The human TBX5 gene mutation database. Hum Mutat 2005;26:397.

28. Foley C, Schofield I, Eglon G, et al. Charcot-Marie-Tooth disease in Northern England. J Neurol Neurosurg Psychiatry 2012;83:572-573.

29. Norwood FL, Harling C, Chinnery PF, et al. Prevalence of genetic muscle disease in Northern England: in-depth analysis of a muscle clinic population. Brain 2009;132:3175-3186.

30. Pearn J. Incidence, prevalence, and gene frequency studies of chronic childhood spinal muscular atrophy. J Med Genet 1978;15:409-413.

31. Dierick I, Baets J, Irobi J, et al. Relative contribution of mutations in genes for autosomal dominant distal hereditary motor neuropathies: a genotype-phenotype correlation study. Brain 2008;131:1217-1227.

32. Van Den Bosch L, Timmerman V. Genetics of motor neuron disease. Curr Neurol Neurosci Rep 2006;6:423-431.

33. Whittaker RG, Herrmann DN, Bansagi B, et al. Electrophysiologic features of SYT2 mutations causing a treatable neuromuscular syndrome. Neurology 2015;85:1964-1971.

34. Ermanoska B, Motley WW, Leitão-Gonçalves R, et al. CMTassociated mutations in glycyl- and tyrosyl-tRNA synthetases exhibit similar pattern of toxicity and share common genetic modifiers in Drosophila. Neurobiol Dis 2014;68:180-189.

35. Sleigh JN, Grice SJ, Burgess RW, et al. Neuromuscular junction maturation defects precede impaired lower motor neuron connectivity in Charcot-Marie-Tooth type 2D mice. Hum Mol Genet 2014;23:2639-2650.

36. Barwick KE, Wright J, Al-Turki S, et al. Defective presynaptic choline transport underlies hereditary motor neuropathy. Am J Hum Genet 2012;91:1103-1107.

37. Ekenstedt KJ, Becker D, Minor KM, et al. An ARHGEF10 deletion is highly associated with a juvenile-onset inherited polyneuropathy in Leonberger and Saint Bernard dogs. PLoS Genet 2014;10:e1004635.

38. Pugliese-Pires PN, Tonelli CA, Dora JM, et al. A novel STAT5B mutation causing GH insensitivity syndrome associated with hyperprolactinemia and immune dysfunction in two male siblings. Eur J Endocrinol 2010;163:349-355.

39. Kalita A, Gupta S, Singh P, et al. IGF-1 stimulated upregulation of cyclin D1 is mediated via STAT5 signaling pathway in neuronal cells. IUBMB Life 2013;65:462-471.

40. Goebbels S, Oltrogge JH, Wolfer S, et al. Genetic disruption of Pten in a novel mouse model of tomaculous neuropathy. EMBO Mol Med 2012;4:486-499. 


\title{
Neurology
}

\author{
Genetic heterogeneity of motor neuropathies \\ Boglarka Bansagi, Helen Griffin, Roger G. Whittaker, et al. \\ Neurology 2017;88;1226-1234 Published Online before print March 1, 2017 \\ DOI 10.1212/WNL.0000000000003772
}

This information is current as of March 1, 2017

\begin{tabular}{|c|c|}
\hline $\begin{array}{l}\text { Updated Information \& } \\
\text { Services }\end{array}$ & $\begin{array}{l}\text { including high resolution figures, can be found at: } \\
\text { http://n.neurology.org/content/88/13/1226.full }\end{array}$ \\
\hline Supplementary Material & $\begin{array}{l}\text { Supplementary material can be found at: } \\
\text { http://n.neurology.org/content/suppl/2017/03/01/WNL.0000000000003 } \\
\text { 772.DC1 }\end{array}$ \\
\hline References & $\begin{array}{l}\text { This article cites } 40 \text { articles, } 11 \text { of which you can access for free at: } \\
\text { http://n.neurology.org/content/88/13/1226.full\#ref-list- } 1\end{array}$ \\
\hline Citations & $\begin{array}{l}\text { This article has been cited by } 2 \text { HighWire-hosted articles: } \\
\text { http://n.neurology.org/content/88/13/1226.full\#\#otherarticles }\end{array}$ \\
\hline Subspecialty Collections & $\begin{array}{l}\text { This article, along with others on similar topics, appears in the } \\
\text { following collection(s): } \\
\text { All clinical neurophysiology } \\
\text { http://n.neurology.org/cgi/collection/all_clinical_neurophysiology } \\
\text { All Genetics } \\
\text { http://n.neurology.org/cgi/collection/all_genetics } \\
\text { EMG } \\
\text { http://n.neurology.org/cgi/collection/emg } \\
\text { Peripheral neuropathy } \\
\text { http://n.neurology.org/cgi/collection/peripheral_neuropathy }\end{array}$ \\
\hline Permissions \& Licensing & $\begin{array}{l}\text { Information about reproducing this article in parts (figures,tables) or in } \\
\text { its entirety can be found online at: } \\
\text { http://www.neurology.org/about/about_the_journal\#permissions }\end{array}$ \\
\hline Reprints & $\begin{array}{l}\text { Information about ordering reprints can be found online: } \\
\text { http://n.neurology.org/subscribers/advertise }\end{array}$ \\
\hline
\end{tabular}

Neurology $\mathbb{B}$ is the official journal of the American Academy of Neurology. Published continuously since 1951, it is now a weekly with 48 issues per year. Copyright Copyright ( 2017 The Author(s). Published by Wolters Kluwer Health, Inc. on behalf of the American Academy of Neurology. All rights reserved. Print ISSN: 0028-3878. Online ISSN: 1526-632X.

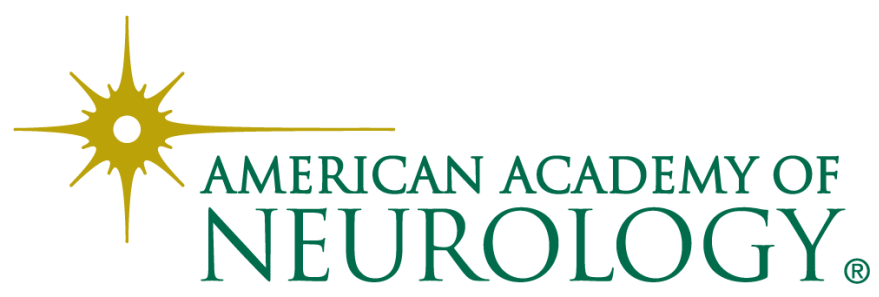

